05,01

\title{
Магнитооптические свойства и фотолюминесценция микропроводов (PrDy)(FeCo)B
}

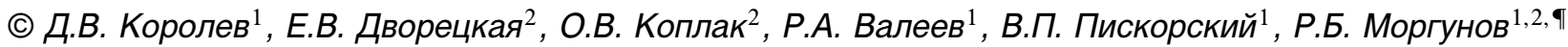 \\ ${ }^{1}$ Всероссийский институт авиационных материалов, \\ Москва, Россия \\ ${ }^{2}$ Институт проблем химической ффизики РАН, \\ Черноголовка, Россия \\ ฯ E-mail: morgunov2005@yandex.ru
}

Поступила в Редакцию 25 ноября 2020 г.

В окончательной редакции 25 ноября 2020 г.

Принята к публикации 27 ноября 2020 г.

\begin{abstract}
Микропровода $(\mathrm{PrDy})(\mathrm{FeCo}) \mathrm{B}$, не содержащие железных включений и ядра, получены экстрагированием из капли расплава $(\mathrm{PrDy})(\mathrm{FeCo}) \mathrm{B}$ при пониженной скорости охлаждения. В объеме микропроводов идентифицированы включения кристаллических фаз $(\mathrm{PrDy})_{2}(\mathrm{CoFe})_{14} \mathrm{~B}$, магнитной фазы Лавеса $\mathrm{Dy}(\mathrm{FeCo})_{2}$ и люминесцирующих под действием ультрафиолетового излучения (УФ) включения фаз $\operatorname{Pr}_{2} \mathrm{O}_{3}$ и $\mathrm{Dy}_{2} \mathrm{O}_{3}$. Получены распределения поперечной и продольной составляющих намагниченности вдоль микропровода, которое регистрировалось для различных направлений внешнего магнитного поля с помощью магнитооптической индикаторной пленки и магнитооптического эффекта Керра. В микропроводах шириной менее $70 \mu \mathrm{m}$ продольное внешнее поле вызывает модуляцию поперечной намагниченности, соответствующую образованию цилиндрических доменов. Сосуществование продольной и радиальной намагниченностей было обнаружено по изменению угла падения и длины волны микроскопа Керра. В более широких микропроводах шириной $\sim 150 \mu \mathrm{m}$ поверхностных радиальных доменов не обнаружено. Обнаружена стимулированная ультрафиолетом фотолюминесценция включений оксидов $\operatorname{Pr}_{2} \mathrm{O}_{3}$ и $\mathrm{Dy}_{2} \mathrm{O}_{3}$, имеющихся, как на поверхности, так и в объеме микропровода.
\end{abstract}

Ключевые слова: микропровода, редкоземельные магниты, доменная структура, эффект Керра, фотолюминесценция.

DOI: 10.21883/FTT.2021.04.50715.247

\section{1. Введение}

Ферромагнитные микропровода привлекают внимание, как новыми фундаментальными явлениями, так и широким практическим применением. В последние годы в ферромагнитных микропроводах были обнаружена высокоскоростная магнитная память $[1,2]$, сверхбыстрое распространение доменов $[3,4]$, гигантский магнитоимпедансный эффект $[5,6]$ и другие совершенно новые явления. Были предложены и успешно реализованы возможные применения магнитных микропроводов в биологии в качестве микроманипуляторов клеток [7,8], датчиков слабого магнитного поля [9], температуры [10] и напряжения [11]. Дорожная карта магнетизма [12] предсказывает развитие этих многослойных микропроводов, сочетающих переходные и редкоземельные металлы, разработку магнитно-модулированных микропроводных структур и методов их получения, применение микропроводов в биомедицинских технологиях [13] и развитие техники модулирования их магнитных свойств [14,15]. Bce упомянутые выше приложения могут быть значительно ускорены и улучшены за счет оптического считывания намагниченности.

Магнитная структура большинства ранее исследованных ферромагнитных микропроводов, состоящих из магнито-мягких переходных металлов $\mathrm{Fe}, \mathrm{CoFeSi}, \mathrm{CoFe}$, Со и т.п., содержит внутреннее ядро, намагниченное вдоль главной оси микропровода, и внешнюю оболочку того же химического состава с мозаичной намагниченностью, контролируемой поверхностными доменами. Размеры однодоменного внутреннего ядра и намагниченности поверхности зависят от механических напряжений на границе раздела. Форма и размер поверхностных магнитных доменов контролируются магнитной кристаллической и магнитоупругой анизотропиями [15]. Положительная магнитострикция приводит к радиальному намагничиванию доменов оболочки, тогда как отрицательная магнитострикция обеспечивает круговое (циркулярное) намагничивание оболочки [16]. В магнитожестких редкоземельных магнитах семейства RE-TM-B (TM - переходные металлы, RE - редкоземельные металлы) ранее была установлена положительная магнитострикция, превышающая на порядок величины магнитострикции в микропроводах, изготовленных только из переходных металлов. По этой причине можно ожидать радиального намагничивания поверхностных слоев микропроводов (PrDy)(FeCo)B.

Недавно мы сообщали о создании микропроводов круглой формы, содержащих ядро из $\alpha$-Fe и оболочку $(\mathrm{PrDy})(\mathrm{FeCo}) \mathrm{B}[17]$. В [17] интегральная намагни- 
$a$

$b$

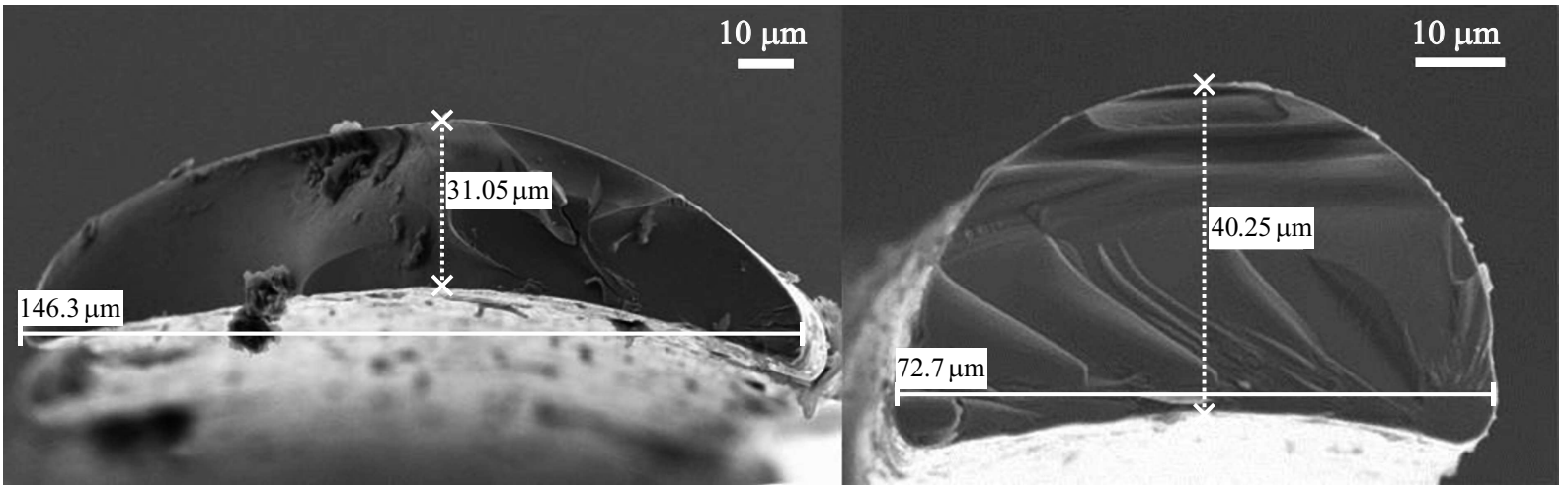

Рис. 1. Изображения (PrDy)(FeCo)В микропроводов разной ширины $72 \mu \mathrm{m}(a)$ и $146 \mu \mathrm{m}(b)$, полученные сканирующим электронным микроскопом.
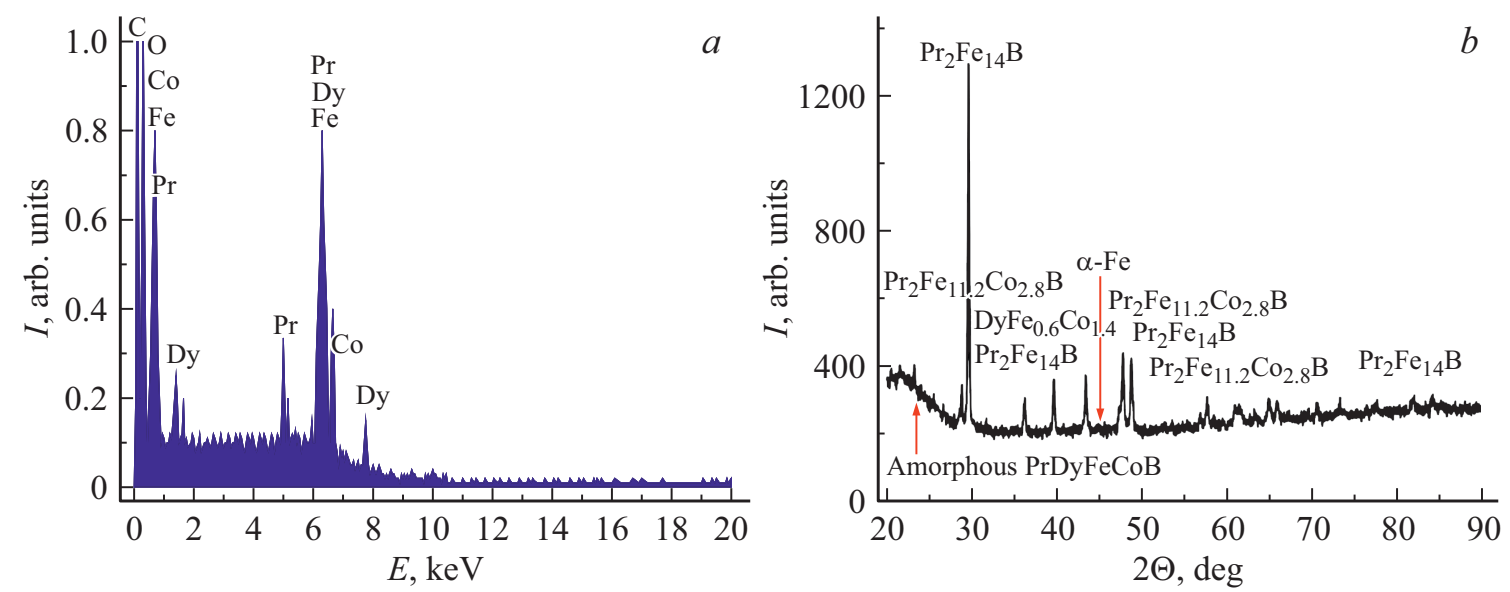

Рис. 2. Спектр $\operatorname{EDX}(a)$ и спектр рентгеновской дифракции $(b)$ микропровода 2.

ченность микропроводов регистрировалась с помощью СКВИД-магнитометра, а в настоящей работе мы использовали магнитооптические методы. В этой работе были выращены линзовидные аморфные микропровода (рис. $1 a, b)$, свободные от фазы $\alpha$-Fе. Работа направлена на установление химической, фазовой и доменной структур в редкоземельных микропроводах $(\mathrm{PrDy})(\mathrm{FeCo}) \mathrm{B}$, не содержащих фазы $\alpha$-Fe.

\section{2. Методика экспериментов и приготовление образцов}

Капля расплава создавалась пучком электронов высокой энергии, сфокусированным на краю спеченной заготовки PrDyFeCoB. Детали первичной подготовки слитка также описаны в [17]. Микропровода выращивались путем быстрого охлаждения капли расплава $(\mathrm{PrDy})(\mathrm{FeCo}) \mathrm{B}$, стекающей на латунный цилиндр, вращающийся с линейной скоростью $\sim 40 \mathrm{~m} / \mathrm{s}$. В настоящей работе были проанализированы микропровода $146 \mu \mathrm{m}$ (образец 1) и $72 \mu \mathrm{m}$ (образец 2) одинаковой длины $1300 \mu \mathrm{m}$ (рис. 1, $a, b$ ). Форма поперечного сечения микропроводов отличается от цилиндрической формы, наблюдаемой в [17], из-за низкой скорости охлаждения, обеспечивающей растекание расплава по холодному цилиндру раньше, чем расплав затвердевает. В [18] была описана эволюция растекающейся капли $\mathrm{PrDyFeCoB}$ в форме линзы в зависимости от вязкости и плотности жидкости расплава $\mathrm{PrDyFeCoB}$, в свою очередь, зависящих от температуры.

На рис. 2, $а$ представлен типичный спектр энергодисперсионного анализа (EDX), полученный в поперечном сечении микропровода. Bce химические элементы Dy, $\mathrm{Pr}, \mathrm{Co}, \mathrm{Fe}$, присутствующие в исходном расплаве, обнаружены в микропроводах (рис. 2,a). Вклады кислорода и углерода обычно имеются в вакуумной камере и их трудно отделить от примесей в образце. Измерение спектра EDX в разных частях образца показало, что имеет место однородное распределение химических элементов $\mathrm{Pr}, \mathrm{Dy}, \mathrm{Fe}$ и Co без их разделения на разные фазы. Спектр дифракции рентгеновских лучей (XRD) указывает на присутствие аморфной матрицы $\mathrm{PrDyFeCoB}$, соответ- 
ствующей широкому гало и поликристаллическим включениям различных ферромагнитных фаз, соответствующим узким пикам (рис. 2,b). Пики были идентифицированы с помощью Match Software. Основная магнитная фаза 2-14-1 представлена несколькими соответствующими модификациями $\left(\operatorname{Pr}_{y} \mathrm{Dy}_{1-y}\right)_{2}\left(\mathrm{Fe}_{x} \mathrm{Co}_{1-x}\right)_{14} \mathrm{~B}$ с различными атомными долями $\mathrm{Fe}, \mathrm{Co}$ и $\mathrm{Pr}$, Co. Присутствует слабомагнитная фаза Лавеса $\mathrm{Dy}\left(\mathrm{Fe}_{x} \mathrm{Co}_{1-x}\right)_{2}$. B отличие от микропровода, описанного в [17], в этой статье не было обнаружено следов $\alpha$-Fe (см. вертикальную стрелку на рис. $2, b$ ). Полученные данные позволяют предположить, что микропровод состоит из аморфной матрицы PrDyFeCoB с поликристаллическими включениями RE-TM-B, хаотически распределенными в объеме микропровода.

Для визуализации компоненты намагниченности магнитного поля, перпендикулярной микропроводу, использовали метод магнитооптической индикаторной пленки (MOIF), который основан на магнитооптическом эффекте Фарадея в оптически прозрачной пленке граната, подвергнутой воздействию магнитного поля микропровода. Локальная намагниченность визуализировалась с помощью поляризационного микроскопа, фокусирующего отраженный луч линейно поляризованного света. Поверхность микропровода была покрыта зеркалом из оксида алюминия и эпитаксиальной пленкой железоиттриевого граната, легированной $\mathrm{Bi}$, для обнаружения компонента намагниченности микропровода, перпендикулярного поверхности. Намагниченность индикаторной пленки лежит в ее плоскости в отсутствие внешнего магнитного поля. В присутствии магнитного поля микропровода нормальная составляющая поля визуализируется из-за отклонения намагниченности пленки граната от плоскостной ориентации. Подробное описание метода представлено в [19]. В экспериментах MOIF внешнее поле катушек Гельмгольца прикладывалось вдоль или перпендикулярно к главной оси микропровода.

При исследовании эффекта Керра намагниченность сканировали вдоль оси микропровода с помощью микроскопа Durham Nano-MOKE3 в меридиональной и полярной геометриях (магнитное поле было направлено вдоль оси микропровода, поляризация падающего лазерного луча и ось микропровода лежат в одной плоскости). Диаметр сфокусированного лазерного пятна составлял $3 \mu \mathrm{m}$. Использовали лазерный луч с длиной волны $660 \mathrm{~nm}$ и УФ-микроскоп с ртутной лампой сверхвысокого давления $130 \mathrm{~W}$ с максимальной длиной волны излучения $\sim 400 \mathrm{~nm}$ (УФ-излучение). Глубина проникновения света не превышала $\sim 20-30 \mathrm{~nm}$. Метод МОКЕ позволяет измерять намагниченность ионов металлов из-за процессов переизлучения, сопровождающих отражение света, в то время как вышеописанный метод MOIF позволяет определять поле рассеяния, создаваемое микропроводом. Полный магнитный момент микропровода определялся магнитометром MPMS XL Quantum Design при $300 \mathrm{~K}$ и в диапазоне магнитного поля $\pm 2 \mathrm{kOe}$. Сканирующий электронный микроскоп SUPRA 25 Zeiss был использован для получения СЭМ-изображений микропроводов.

\section{3. Результаты}

\section{1. Доменная структура, установленная методом магнитооптической индикаторной пленки}

Петля гистерезиса большого микропровода 1 была шире по сравнению с петлей микропровода 2 (рис. 3 ). Асимметрия петли гистерезиса микропровода 1 указывает на поле смещения $H_{b} \sim 24$ Ое и коэрцитивную силу $H_{c} \sim 44$ Ое. Микропровод 2 имеет коэрцитивную силу $H_{c} \sim 5 \mathrm{Oе}$ и нулевое поле смещения. Точка расхождения нисходящей и восходящей ветвей гистерезиса была найдена в поле 20-25Ое (вставка на рис. 3). Поскольку химический состав, спектры дифракции рентгеновских лучей и намагниченности насыщения микропроводов 1 и 2 не отличаются друг от друга, мы можем сделать вывод о влиянии формы микропровода на петлю гистерезиса. Микропровод 2 имеет петлю гистерезиса высокой прямоугольности, очень похожую на петлю, наблюдаемую в цилиндрическом микропроводе [17]. Намагниченность насыщения микропроводов $M_{s} \sim 200 \mathrm{emu} / \mathrm{cm}^{3}$ была заметно меньше, чем намагниченность $M_{s} \sim 700 \mathrm{emu} / \mathrm{cm}^{3}$, ранее наблюдавшаяся в объемном спеченном магните аналогичного состава [18]. Этот факт подтверждает большую долю аморфной фазы $\sim 80 \%$ и низкую долю кристаллических включений с хаотично распределенной легкой осью намагничивания. Методом MOIF было получено распределение поперечной составляющей намагниченности в микропроводах разного диаметра. На рис. 4 представлены магнитооптические изображения микропроводов 1 (линии 1 и 2) и 2 (линии 3 и 4) в продольном $(1,4)$ и поперечном $(2,3)$ внешнем полях. Магнитное поле $H$ изменялось от -150 до +150 Ое. На рис. 4 введены координаты $x, y, z$,

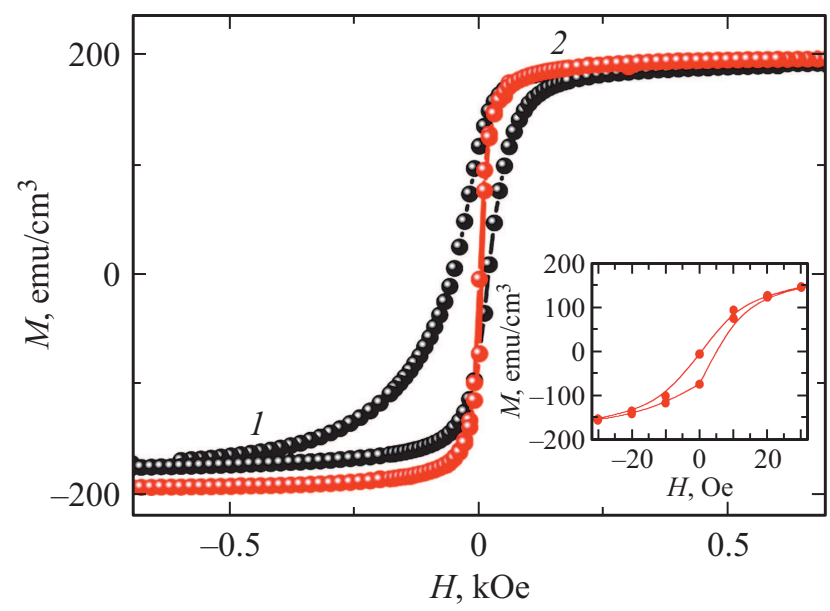

Рис. 3. Петли гистерезиса микропроводов 1 и 2. 


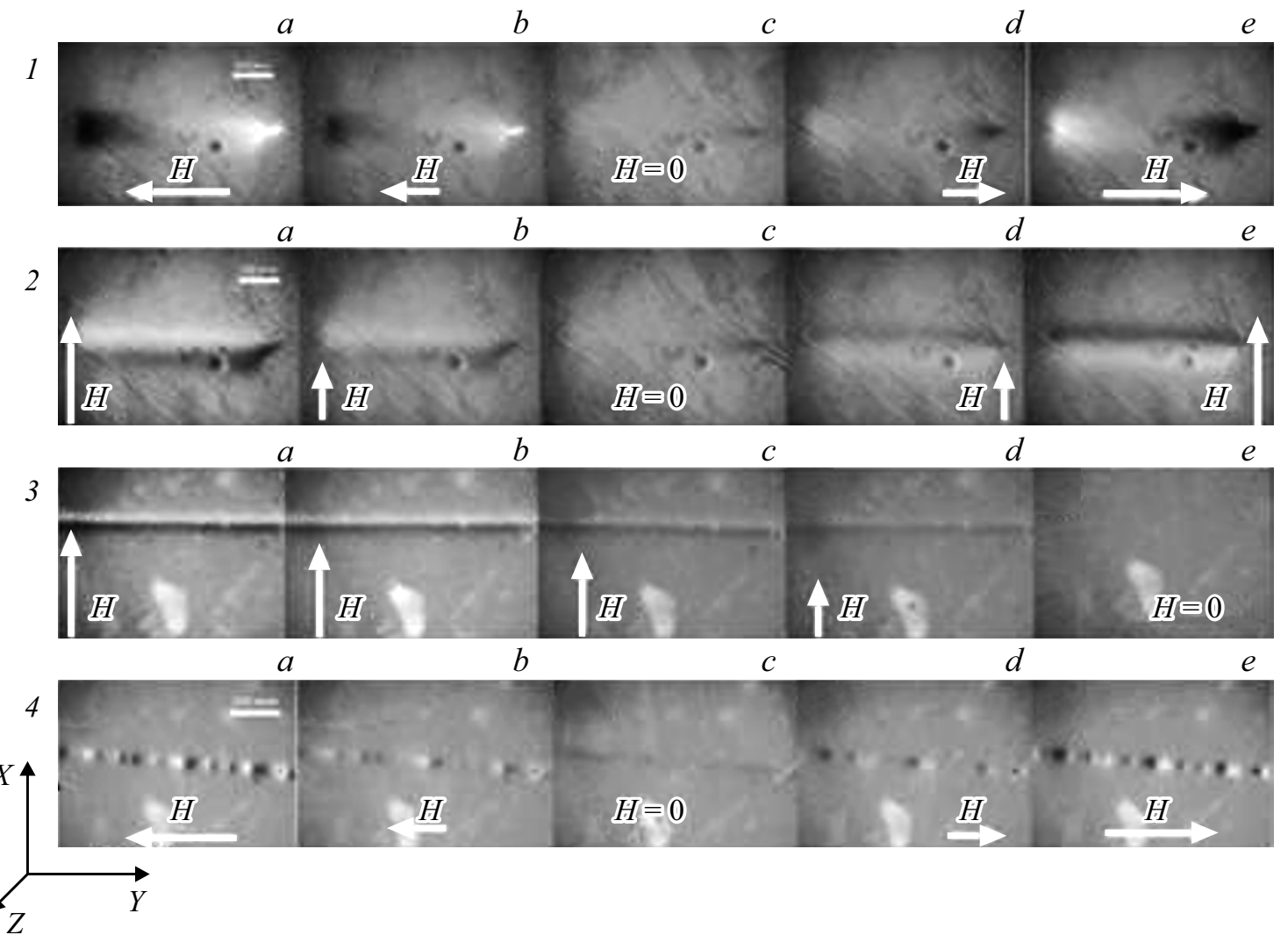

Рис. 4. MOIF-изображения микропровода $1(1,2)$ и микропровода $2(3,4)$ в продольной $(1,3)$ и поперечной $(2,4)$ ориентациях внешних магнитных полей $140(a), 70(b), 0(c),-70(d),-150$ Ое $(e)$. Направления магнитного поля показаны стрелками.

которые будут использоваться далее. Широкий микропровод 1 демонстрирует типичное для двухполюсного сплошного цилиндра распределение намагниченности в продольных магнитных полях $150(a), 70(b), 0$ (c), $40(d), 150$ Oе $(e)$ (рис. 4, строка 1). В поперечном магнитном поле имеется соответствующая намагниченность, перпендикулярная микропроводу (рис. 4, строка 2). Аналогичные распределения намагниченности в поперечном магнитном поле $150(a), 70(b), 30(c)$, $10(d)$, 0 Ое $(e)$ были обнаружены в микропроводе 2 (рис. 4, строка 3). Однако в продольном магнитном поле тонкий микропровод 2 демонстрирует многодоменную структуру в магнитных полях $140(a), 70(b), 0$ (c), $-70(d),-150$ Ое $(d)$ (строка 4 на рис. 4$)$. В отсутствие магнитного поля многодоменность исчезает, а увеличение магнитного поля, напротив, вызывает увеличение количества черных и белых полос. Изменение направления поля на противоположное приводит к смене темных полос на светлые (рис. 4, линия 4). Увеличение магнитного поля не меняет положения магнитной неоднородности. Поскольку сканирование с помощью СЭМ не выявило неоднородности распределения материала, можно предположить, что мы наблюдаем радиальные домены, подобные тем, которые были обнаружены в [20]. Распределения сигнала MOIF, сканированного в поперечном и продольном направлениях в микропроводе 1 и 2 в продольном магнитном поле, представлены на рис. $5, a, b$ соответственно. Изменение полярности поля вызывает изменение полюсов намагниченности. В описанных выше экспериментах доменная структура не наблюдается, т.е. намагниченность микропровода соответствует однодоменному поведению.

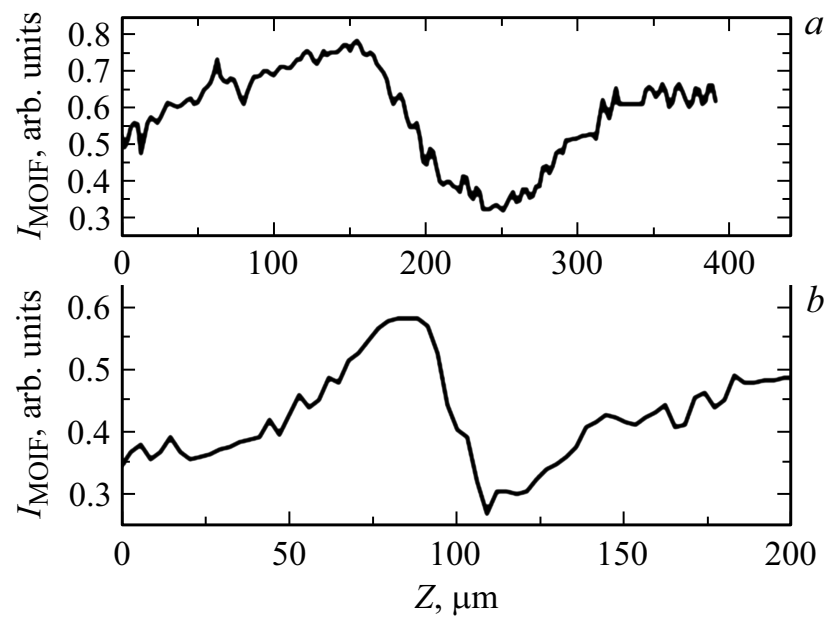

Рис. 5. Распределение сигнала MOIF, сканированного в поперечном направлении вдоль оси $z$, в микропроводах $1(a)$ и $2(b)$, помещенных в поперечное магнитное поле. 

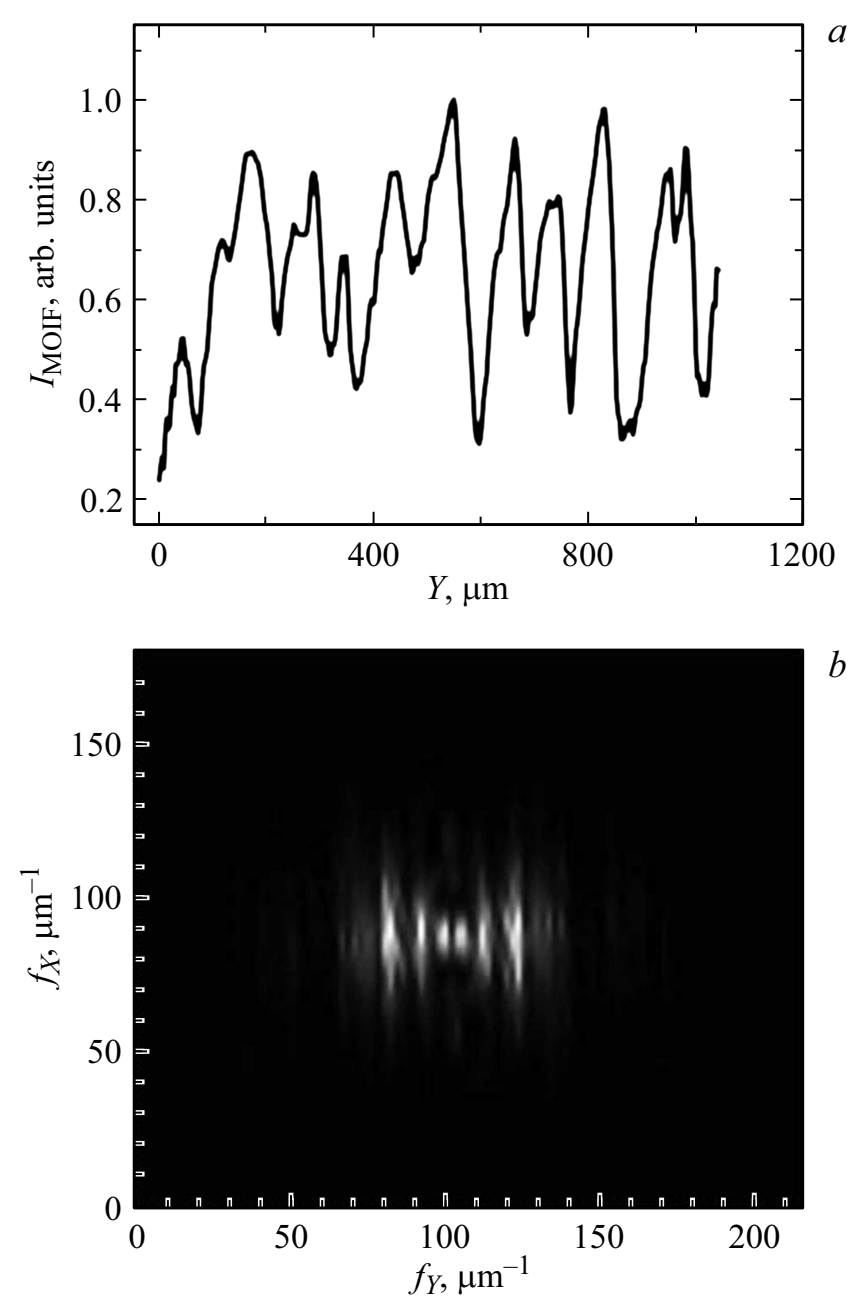

Рис. 6. Распределение сигнала MOIF, сканированного в продольном направлении по оси $y$ в микропроводе 2 , помещенном в продольное магнитное поле 300 Ое $(a)$, Фурье-образ распределения сигнала MOIF $(b)$.

В отличие от микропровода 1, в тонком микропроводе 2 продольное магнитное поле создает многодоменную магнитную структуру (рис. 4, линия 4). Мы выполнили быстрое преобразование Фурье (БПФ) профиля MOIF, сканированного вдоль оси тонкого микропровода (рис. 6,a). Частотное распределение Фурье представлено на рис. $6, b$. На изображении БПФ можно выделить несколько гармоник с пространственными частотами $0.08,0.09$ и $0.10 \mu \mathrm{m}^{-1}$. Эти значения соответствуют сумме синусоидальных гармоник периодической намагниченности с пространственным периодом $125 \mu \mathrm{m}$, близкими к диаметру микропровода.

\section{2. Продольная составляющая локальной намагниченности}

Поскольку доменная структура наблюдалась в тонких микропроводах, в этом разделе мы использовали образец 2 для исследования распределения намагниченно- сти методом MOKЕ. Микроскопия Керра основана на анализе поляризации красного лазерного луча $620 \mathrm{~nm}$, отраженного поверхностью микропровода. Изображения MOKE, записанные в меридиональной ориентации (см. эскиз на рис. 7), позволяют судить о намагниченности продольной компоненты в оболочке микропровода. Прямоугольная петля гистерезиса в центре микропровода (рис. 7,a) и наклонная петля гистерезиса на конце микропровода (рис. $7, b$ ) сходны с теми, что наблюдались в однодоменных микропроводах с продольной намагниченностью $[21,22]$.

Аморфный материал имеет нулевое коэрцитивное поле из-за хаотической ориентации оси одноионной анизотропии [23]. Хотя намагниченность, определенная с помощью микроскопа Керра, относится к поверхностному аморфному слою, намагниченность этого слоя зависит от поля рассеяния кристаллических включений. Намагниченность этих включений может передаваться аморфной матрице за счет магнитных дипольных и обменных взаимодействий. Смещенные петли гистерезиса, зарегистрированные методами SQUID и MOKE (рис. 3 и рис. 7, $a$ соответственно), подтверждают наличие обмен-
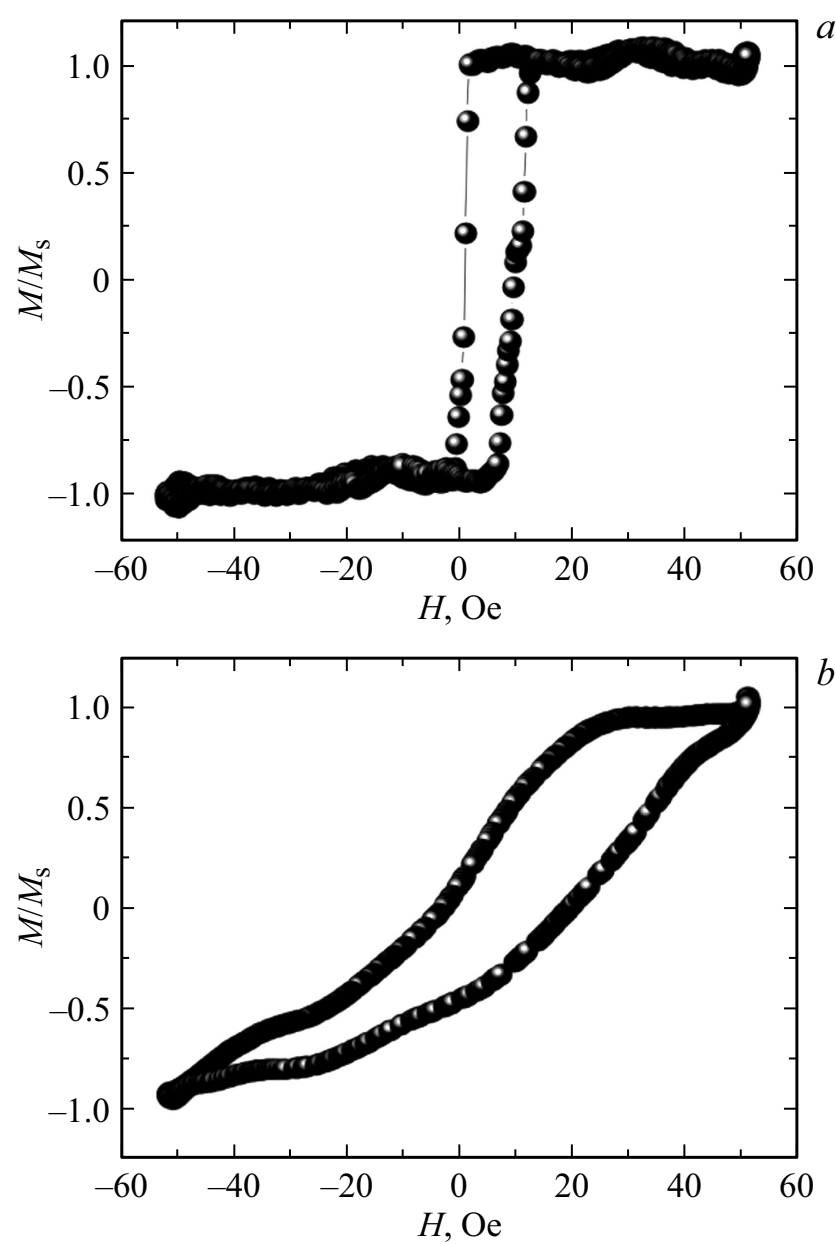

Рис. 7. Локальные петли гистерезиса, записанные в микроскопе Керра в середине микропровода $(a)$ на конце микропровода $2(b)$. 

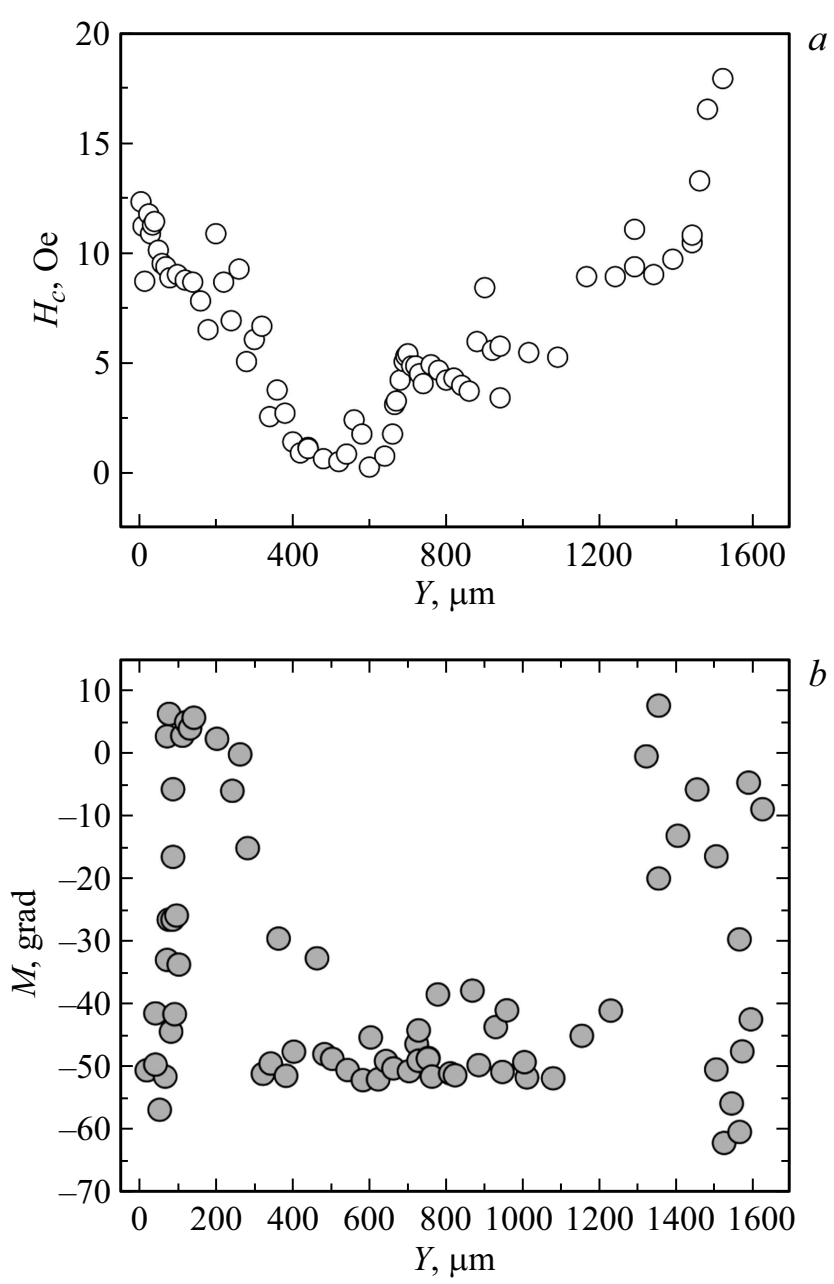

Рис. 8. Коэрцитивное поле $(a)$ и МОКЕ-сигнал, пропорциональный локальной намагниченности в магнитном поле $60 \mathrm{Oe}(b)$, извлеченный из локальных петель гистерезиса, записанных при длине волны $620 \mathrm{~nm}$ в различных точках вдоль микропровода 2.

ной связи между включениями и аморфной матрицей. Эта связь может способствовать перпендикулярной намагниченности, измеряемой методами MOIF и MOKE.

Такие же выводы относительно однодоменного магнитного ядра микропровода были получены из рис. $8, a, b$, где представлены распределения коэрцитивного поля $H_{c}$ и MOIF-сигнала $M$ в магнитном поле $60 \mathrm{Oe}$ в различных точках вдоль микропровода. Сильное увеличение $H_{c}$ и $M$ на концах микропровода соответствует перпендикулярной составляющей магнитного поля, создаваемой замыкающими доменами.

Распространение доменной стенки вдоль сердцевины микропровода наблюдалось в продольном магнитном поле в продольной конфигурации L-MOKE (Laser-MOKE), что соответствует измерению продольной намагниченности микропровода согласно [24]. Изображение микропровода в неполяризованном свете показано на рис. 9, $a$. Серия изображений L-MOKE, записанных с площади $14 \times 225 \mu \mathrm{m}^{2}$ в середине микропровода, приведена на рис. $9, b$ в диапазоне полей от -50 до +50 Ое. Наблюдается распространение магнитного домена от левого конца к правому концу, в зависимости от величины продольного магнитного поля. Обратное распространение доменной стенки наблюдалось при изменении магнитного поля в противоположном направлении. Кривизна поверхности микропровода не влияет на центральную часть изображения, поскольку ширина освещенной части микропровода $14 \mu \mathrm{m}$ (показано белым пунктирным прямоугольником) уже, чем диаметр микропровода $70 \mu \mathrm{m}$. При этом освещенная часть намного шире изучаемой области (рис. 9, $b$ ). Полученные изображения L-MOKE подтверждают интерпретацию прямоугольной петли гистерезиса (рис. 7,a), соответствующей однодоменному поведению в центре микропровода.

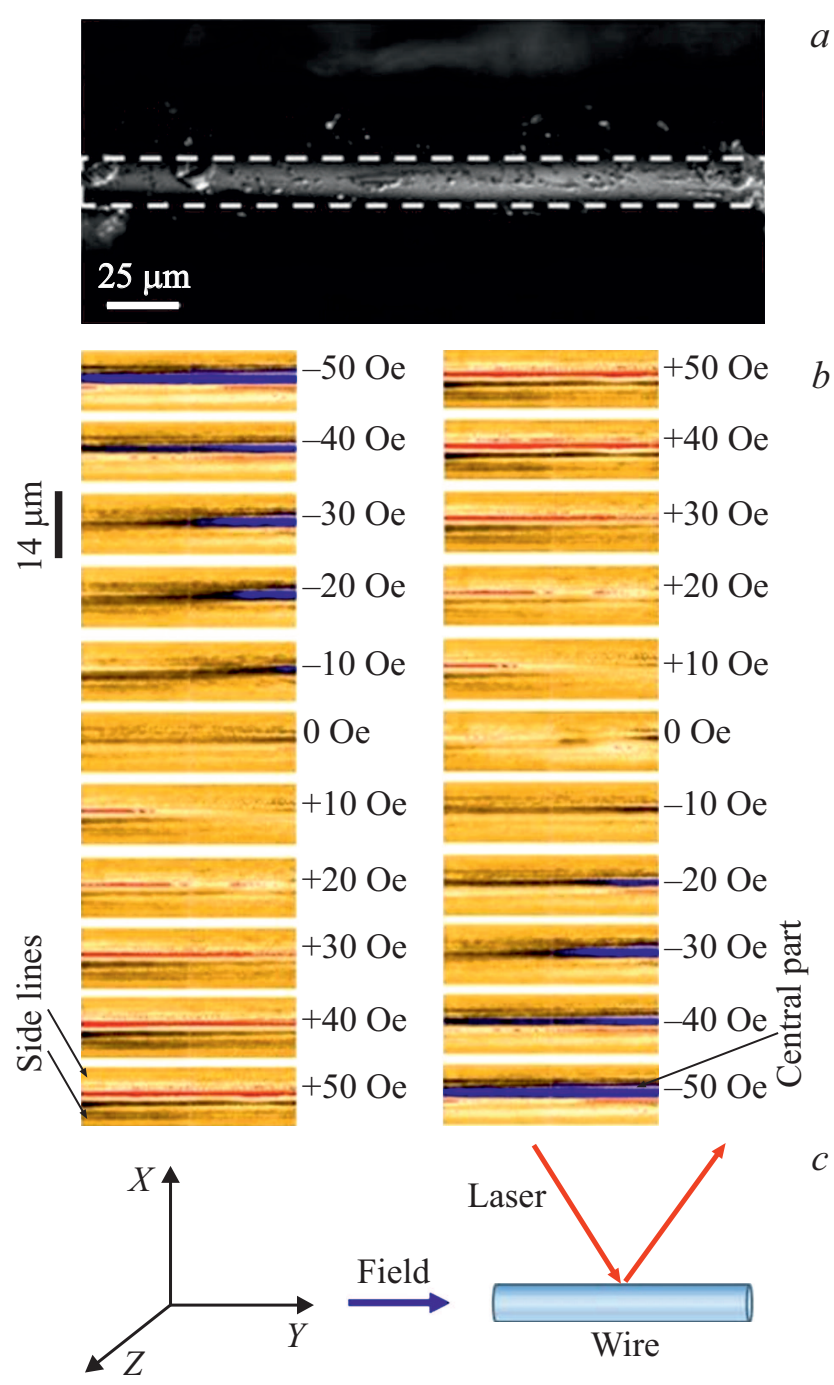

Рис. 9. Оптическое изображение центральной части микропровода 2. Пунктирная линия показывает область, удерживаемую микроскопом Керра $(a)$, изображения L-MOKE, записанные из пунктирной области в магнитном поле от -50 до $+50 \mathrm{Oe}(b)$. Угол падения лазерного луча составлял 60 градусов $(c)$. 
Важным фактором, сильно влияющим на сигнал MOKЕ, является кривизна микропровода. В [25] предложены точные аналитические выражения, описывающие искажения сигнала Керра из-за кривизны поверхности. Отраженный световой луч содержит вклады разных плоскостей отражения, соответствующих разным поляризациям. Основным методом проверки вклада кривизны, предложенным в [25], является сравнение распределения L-MOKE для двух противоположных ориентаций компоненты намагниченности $m_{y}$ На рис. 9, $b$ видно, что центральная часть расширяется из-за изменения поля. Ширина этой части $3 \mu \mathrm{m}$ соответствует отклонению угла падения лазерного луча $\theta \sim 7^{\circ}$, определяемому из выражения $\sin \theta=3 / 70$ в микропроводах диаметром $72 \mu \mathrm{m}$. Эта величина очень мала, и мы можем пренебречь кривизной микропровода, обсуждая сигнал L-MOKE центральной части. Изменение приложенного продольного магнитного поля в противоположном направлении вызывает изменение намагниченности $m_{y}$ в противоположном направлении. Очевидно, что разница между контрастами +50 и -50 Ое на рис. $9, b$ приводит к тому, что центральная часть изображения соответствует полосе при -50 Ое. Это прямое экспериментальное подтверждение того, что центральная фиолетовая часть изображения сигнала МOKE обеспечивается намагничиванием микропровода, а не его кривизной.

Две темные внешние полосы, окаймляющие центральную часть, изменяются при изменении полярности поля. Эти боковые полосы в экспериментах с L-MOKE были описаны в [25] как эффект кривизны микропровода. Полная ширина $14 \mu \mathrm{m}$, захватываемая микроскопом Керра (пунктирный прямоугольник на рис. 9, a), соответствует $\sin \theta \sim 14 / 70$ и $\theta=36^{\circ}$. Этим угловым отклонением нельзя пренебречь в наших экспериментах. Таким образом, боковые темные линии соответствуют влиянию кривизны микропровода на изображение в микроскопе Керра.

Дополнительно был проведен эксперимент L-MOKE в ультрафиолетовом свете $\sim 400 \mathrm{~nm}$ UV-MOKE. В УФ-свете доменов вдоль оси микропровода не наблюдалось. Изменение полярности магнитного поля вызывает светлые и темные контрасты верхней и нижней половин микропровода. Зависимость изображения от внешнего продольного магнитного поля представлена на рис. 10. Увеличение магнитного поля от -50 до +50 Ое приводит к постепенному изменению контраста в верхней и нижней половинах микропровода. Знаки этих вариаций противоположны. В верхней половине интенсивность сигнала МОКЕ увеличивается, а в нижней половине - уменьшается. Это означает, что намагниченности в верхней и нижней половинах вращаются в противоположных направлениях. Когда магнитное поле достигает +25 Ое (поле схлопывания петли гистерезиса на рис. 3), происходит резкая смена темного и светлого контраста верхней и нижней части микропровода. Светлая половина становится темной, а темная нижняя половина становится светлой. Дальнейшее увеличение
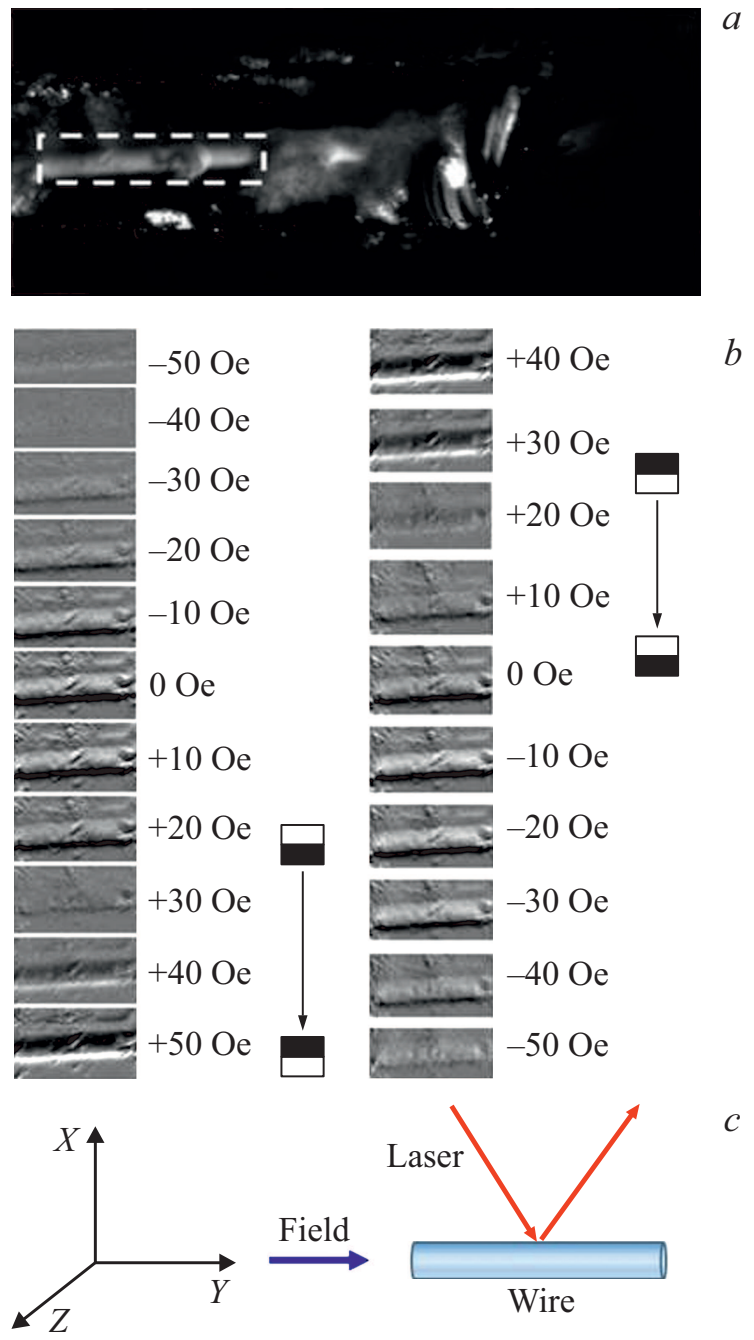

Рис. 10. Изображение микропровода 2 (a); распределения продольной намагниченности, зарегистрированные UV-MOKE в продольном магнитном поле. Чередование черных и белых зон в поле 25 Ое показано на вставках в виде эскизов $(b)$; ориентация светового луча, поля и микропровода $(c)$.

приложенного магнитного поля до 50 Ое не приводит к существенным изменениям. При обратном изменении поля от +50 до $-50 \mathrm{Oe}$, аналогичное резкое изменение полярности намагниченности происходит при $+25 \mathrm{Oe}$ После этого при дальнейшем уменьшении магнитного поля намагниченности в верхней и нижней половинах вращаются в противоположных направлениях, возвращаясь к исходной магнитной конфигурации при -50 Ое. Резкое изменение магнитной полярности микропровода при внешнем продольном поле $25 \mathrm{Oe}$ можно объяснить перемагничиванием внутреннего ядра в поле, соответствующем полю $25 \mathrm{Oe}$, когда SQUID-магнитометр обнаружил расхождение восходящей и нисходящей ветвей микропровода (вставка в рис. 3). Наблюдаемые изображения UV-MOKE можно объяснить тем, что изменение направления намагниченности внутреннего ядра в противоположном направлении вызывает пере- 


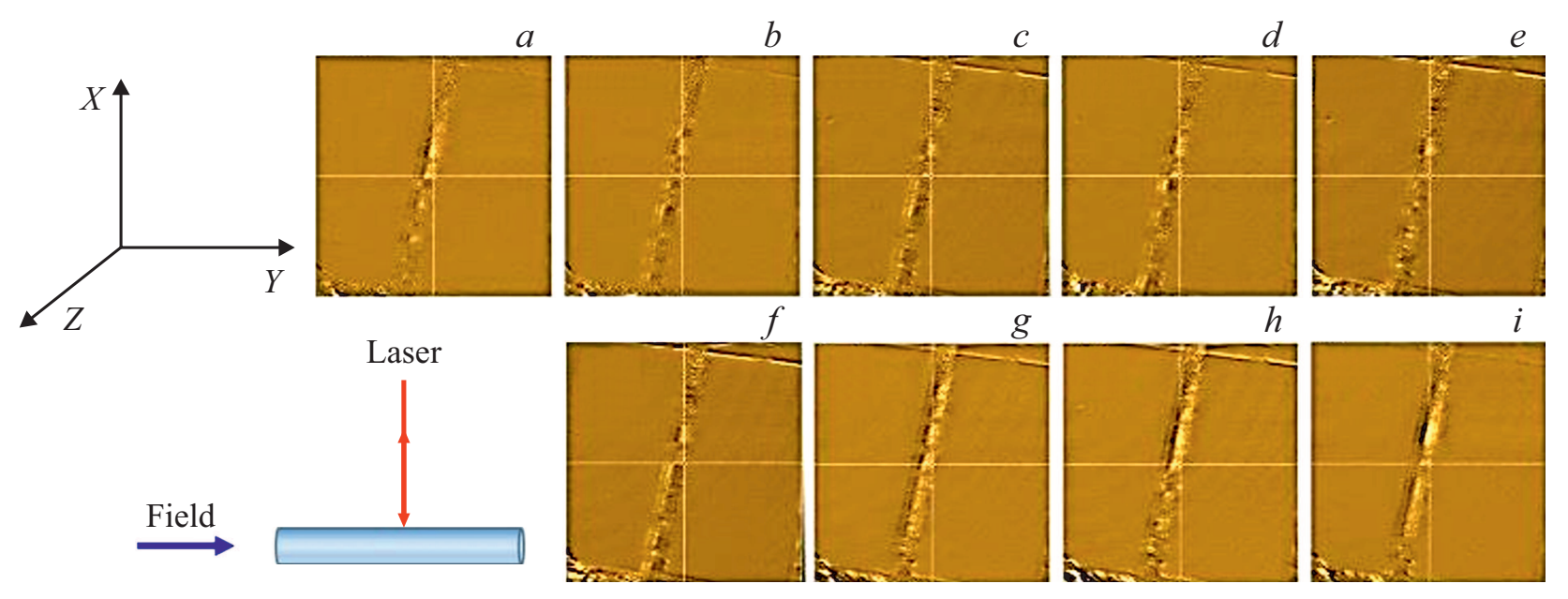

Рис. 11. Изображения Р-МОКЕ, записанные в продольном магнитном поле $-50(a),-40(b),-30(c),-20(d), 0(e), 20(f)$, $30(\mathrm{~g}), 40(h), 50 \mathrm{Oе}(i)$ лазерным лучом с длиной волны $620 \mathrm{~nm}$, направленным перпендикулярно микропроводу. На вставке показаны ориентации поля и светового луча, соответствующие эксперименту Р-МОКЕ.

стройку поверхностных магнитных доменов. Переключение темного и светлого контрастов верхней и нижней половин микропровода в поле $\sim 25$ Ое соответствует расхождению ветвей петли гистерезиса для внутреннего домена (рис. 3). Его резкое перемагничивание при 25 Ое вызывает перераспределение поверхностных доменов.

Различие изображений в микроскопе Керра в видимом и УФ-лучах вызвано разной глубиной проникновения света. Видимый свет, по-видимому, проникает в микропровода глубже, чем УФ-излучение, и при отражении поворот плоскости поляризации оказывается пропорционален продольной намагниченности внутреннего ядра. Напротив, проникновение УФ-света лишь в тонкие приповерхностные слои создает изображение Керра лишь для намагниченности радиальных доменов поверхности.

\section{3. Поперечная составляющая намагниченности}

Изменение ориентации лазерного луча привело к изменению обнаруживаемого распределения намагниченности. Мы также используем полярную ориентацию Керра (Р-MOKE), обнаруживая радиальную намагниченность, чтобы выявить магнитную доменную структуру в микропроводе 2. В этом случае мы наблюдали компоненту намагниченности $m_{z}$, перпендикулярную поверхности микропровода, соответствующий радиальным доменам (рис. 11). Распределение намагниченности в этом случае демонстрирует доменную структуру, аналогичную той, что была обнаружена методом MOIF (рис. 4).

Наблюдаемые изменения полярности намагниченности можно объяснить радиальной намагниченностью оболочки микропровода, конкурирующей с продольной намагниченностью во внутреннем ядре. Таким обра- зом, микропровод из редкоземельных элементов имеет две компоненты намагниченности: 1) продольную намагниченность однодоменного внутреннего сердечника, 2) перпендикулярную намагниченность, соответствующую радиальной намагниченности. Продольная намагниченность была обнаружена с помощью метода L-MOKE, в то время как MOIF и полярная конфигурация P-MOKE выявляют перпендикулярную составляющую, соответствующую цилиндрической доменной структуре.

Как правило, получение изображения намагниченной среды в плоскости значительно сложнее, чем отображение намагниченного материала вне плоскости [24]. Меридиональный L-MOKE на порядок слабее полярного Р-MOKЕ в большинстве металлических магнитных материалов. Сигнал MOKЕ даже небольшой вне осевой намагниченности обычно позволяет избежать примеси меридионального МОКЕ из осевой составляющей намагниченности. Сходство изображения MOIF (рис. 4, строка 4) с изображением Р-МОКЕ на $620 \mathrm{~nm}$ при перпендикулярном падении пучка (рис. 11) позволяет сделать вывод, что с помощью Р-МОКЕ выявляются перпендикулярные микропроводу компоненты намагниченности $m_{z}, m_{x}$.

В случае экспериментов с УФ-светом мы не наблюдали сигнала от внутреннего продольного домена в тех же условиях падения света. Согласно модели Друде, описывающей поглощение видимого света свободными электронами в металлах [26], глубина проникновения ультрафиолетового света меньше, чем у лазера с длиной волны света $620 \mathrm{~nm}$. Можно ожидать 2-3 кратной разницы между глубиной проникновения в видимом и УФ-лучах. По этой причине в УФ-экспериментах мы наблюдаем поверхностное намагничивание радиальных доменов, в то время как видимый свет дает распределение намагниченности внутреннего ядра микропровода. 

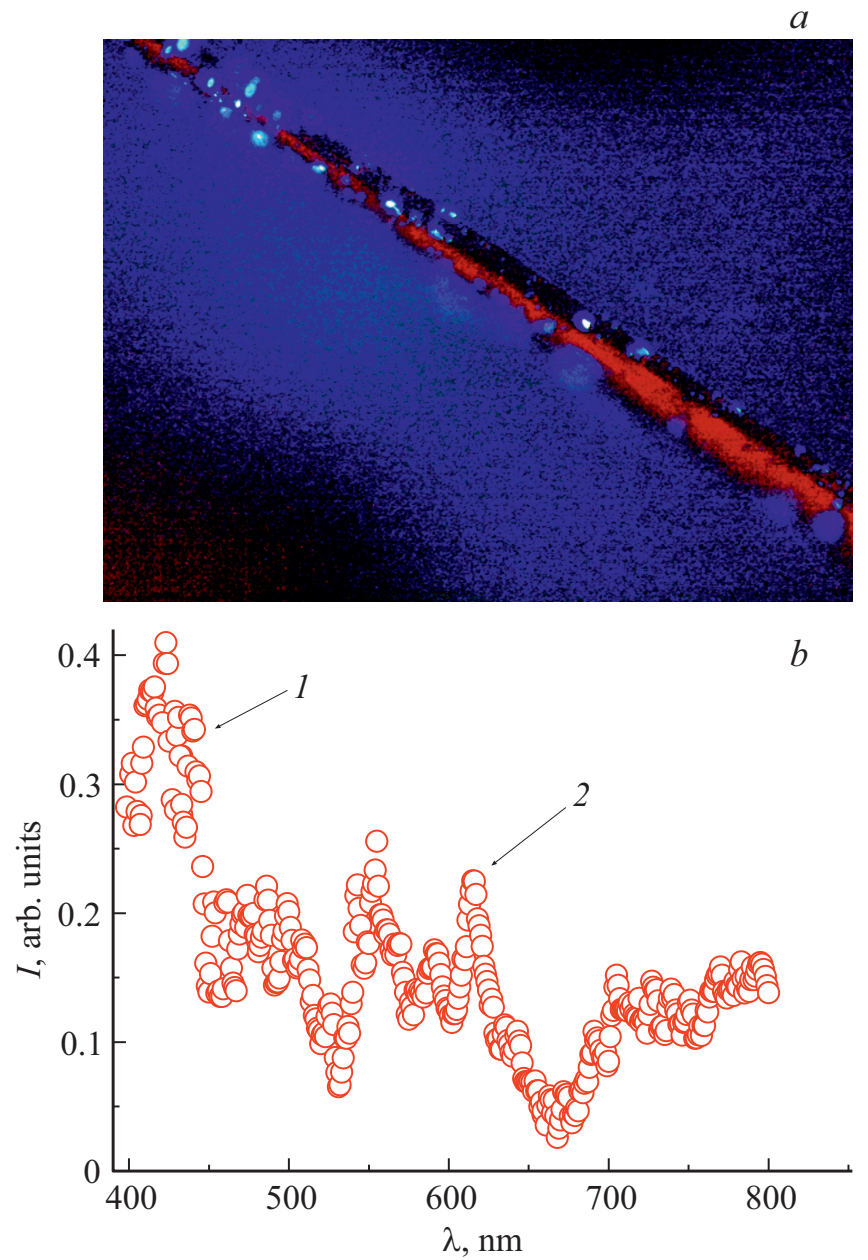

Рис. 12. Свечение кластеров $\mathrm{Dy}_{2} \mathrm{O}_{3}$ и $\mathrm{Pr}_{2} \mathrm{O}_{3}$ на поверхности микропровода 2, вызванное УФ-облучением $(a)$; разностный спектр фотолюминесценции $(b)$. Стрелками 1 и 2 помечены возможные линии спектра, отвечающие синему и красному свечению соответственно.

\section{4. Роль кристаллических микровключений}

Магнитные включения $\left(\operatorname{PryDy}_{1-y}\right)_{2}\left(\mathrm{Fe}_{x} \mathrm{Co}_{1-x}\right)_{14} \mathrm{~B}$ и $\mathrm{Dy}\left(\mathrm{Fe}_{x} \mathrm{Co}_{1-x}\right)_{2}$ и эффекты близости с аморфной матрицей следует учитывать для объяснения магнитного гистерезиса, поля смещения, намагниченности внутреннего сердечника. Сама аморфная матрица имеет среднюю нулевую магнитную анизотропию и нулевую коэрцитивную силу. Поскольку отдельные магнитные включения не были обнаружены методами MOKE или MOIF, и мы наблюдали непрерывное распределение намагниченности, можно предположить, что мелкодисперсные включения в аморфной матрице достаточно малы. Их размер не превышает разрешающей способности контраста микроскопа Керра $\sim 1-2 \mu \mathrm{m}$. Скорее всего, магнитное упорядочение продолжается за пределами размеров включений из-за спин-спинового обменного взаимодействия между электронами проводимости и ионами металлов в аморфной оболочке. Оптические свойства редкоземельных включений контролировались с помощью микроскопа AxioImager.A1 Carl Zeiss. Для регистрации фотолюминесценции микропровода 2 мы использовали ультрафиолетовое (УФ) излучение ртутной лампы (рис. 12,a). УФ-фильтр отсекал излучение с длиной волны более $400 \mathrm{~nm}$. Наиболее интенсивное облучение ртутной лампой в диапазоне $200-400 \mathrm{~nm}$ соответствует длине волны $350 \mathrm{~nm}$. Нижняя граница этого диапазона соответствует границе оптической прозрачности воздуха. Поскольку при записи спектра фотолюминесценции пятно фокусируемого пучка лучей было большим в диаметре $\sim 1 \mathrm{~mm}$, в качестве образца была приготовлена смесь большого количества микропроводов, зафиксированных между кварцевыми стеклами. Спектр фотолюминесценции на отражение снимали дважды: в контрольном опыте с пустым кварцевым держателем, и с держателем, наполненным микропроводами. Далее эти спектры нормировали и вычитали, что позволяло судить о добавочном излучении от микропроводов. На рис. $12, b$ приведен пример разностного спектра, который, хотя и был весьма шумным, при многократных измерениях всегда содержал коротковолновую линию 1 , отвечающую фиолетовому свечению, и серию 2 , соответствующую желто-красному свечению микропровода. В литературе известны спектры излучения ионов $\mathrm{Dy}^{3+}$ при возбуждении светом с длиной волны $350 \mathrm{~nm}$. Такое облучение дает фотолюминесценцию в видимой полосе излучения, расположенной при $\sim 480 \mathrm{~nm}$ (линия 1 ), что соответствует переходу ${ }^{4} \mathrm{~F}_{9 / 2} \rightarrow{ }^{6} \mathrm{HJ}_{15 / 2}[27,28]$. Можно предполагать, что это излучение соответствует локализованным оксидным включениям в наших экспериментах. На рис. $12, b$ также можно различить равномерно распределенное красное излучение. Красная фотолюминесценция, вероятно, соответствует хорошо известному пику с центром при $\sim 610 \mathrm{~nm}$, относящемуся к переходу иона $\mathrm{Pr}^{3+}$ из состояния ${ }^{1} \mathrm{D}_{2}$ в состояние ${ }^{3} \mathrm{H}_{4}$ [29]. Обнаруженная фотолюминесценция требует дополнительных исследований. Оксидные включения могут быть использованы для локального исследования степени окисления, что очень важно для определения магнитных свойств материалов [30].

\section{4. Выводы}

1. Микропровода $(\mathrm{PrDy})(\mathrm{FeCo}) \mathrm{B}$ выращивались методом висячей капли из расплава. Эти микропровода содержат аморфную фазу, а также включения 2-14-1 и 2-1 магнитных фаз и оксидов Pr, Dy. Форма поперечного сечения микропровода сильно зависит от скорости охлаждения, изменяясь от круглой при высокой скорости охлаждения до полос или линзовидного поперечного сечения при низкой скорости охлаждения.

2. Однодоменное состояние внутреннего ядра и расширение центрального домена в увеличивающемся продольном магнитном поле были обнаружены методом L-MOKE с длиной волны $620 \mathrm{~nm}$. Многодоменная маг- 
нитно-модулированная структура поверхностных доменов обнаружена в продольном магнитном поле методами MOIF и P-MOKE с длиной волны $620 \mathrm{~nm}$.

3. Изображение микропровода, полученное в микроскопе Керра в УФ-диапазоне $\sim 430 \mathrm{~nm}$, выявляет радиальную намагниченность поверхностных доменов, направление которой меняется на противоположное в поле $25 \mathrm{Oe}$, что соответствует критическому полю перемагничивания магнитного ядра микропровода, определенному независимо в SQUID-магнетометре. Структура поверхностных доменов чувствительна к направлению намагниченности ядра микропровода.

5. Продольная и радиальная намагниченности сосуществуют в микропроводах $(\mathrm{PrDy})(\mathrm{FeCo}) \mathrm{B}$ с небольшим диаметром 20-70 $\mu \mathrm{m}$, в то время как в микропроводах диаметром $150 \mu \mathrm{m}$ радиальная доменная структура не наблюдается.

6. Интенсивная синяя и красная фотолюминесценция включений $\mathrm{Dy}_{2} \mathrm{O}_{3}$ и $\mathrm{Pr}_{2} \mathrm{O}_{3}$ наблюдается под действием УФ-излучения, как в исходных микропровоодах, так и в микропроводах с удаленным поверхностным слоем. Это указывает на объемный характер распределения светящихся включений в микропроводах.

\section{Благодарности}

Авторы признательны А.Д. Таланцеву за помощь в получении данных на микроскопе Керра.

\section{Финансирование работы}

Работа поддержана Российским фондом фундаментальных исследований „Стабильность“ (проект 20-32$70025)$ и грантом Президента Российской Федерации для ведущих научных школ 2644.2020.2. Работа выполнена в рамках темы № AААА-А19-119111390022-2 госзадания ИПХФ РАН.

\section{Конфликт интересов}

Авторы заявляют, что у них нет конфликта интересов.

\section{Список литературы}

[1] K. Moon, D. Kim, C. Kim, D. Kim, S. Choe, C. Hwang. J. Phys. D 50, 125003 (2017).

[2] P. Corte-León, J.M. Blanco, V. Zhukova, M. Ipatov, J. Gonzalez, M. Churyukanova, S. Taskaev, A. Zhukov. Sci. Rep. 9, 12427 (2019)

[3] R. Varga, A. Zhukov, J.M. Blanco, V. Zhukova, M. Ipatov, J. Gonzalez, V. Vojtaník. Phys. Rev. B 74, 212405 (2006).

[4] V. Zhukova, P. Corte-Leon, M. Ipatov, J.M. Blanco, L. Gonzalez-Legarreta, A. Zhukov. Sensors 19, 21, 4767 (2019).

[5] H. Peng, F. Qin, M. Phan. Ferromagnetic Microwire Composites. Engineering Materials and Processes, Switzerland. (2016). 245 p.

[6] S.V. Shcherbinin, S.O. Volchkov, A.A. Chlenova, G.V. Kurlyandskaya. Key Eng. Mater. 826, 19 (2019).
[7] T. Henighan, A. Chen, G. Vieira, A.J. Hauser, F.Y. Yang, J.J. Chalmers, R. Sooryakumar. Biophys. J. 98, 3, 412 (2010).

[8] P. Kollmannsberger, B. Fabry. Rev. Sci. Instrum. 78, 114301 (2007).

[9] M. Vazquez. Magnetic Nano- and Microwires, Design, Synthesis, Properties and Applications, Woodhead Publishing, Cambridge. (2015). 997 p.

[10] M. Vazquez, C. Gomez-Polo, D.-X. Chen, A. Hernando. IEEE Trans. Magn. 30, 2, 907 (1994).

[11] M. Vazquez, A. Hernando. J. Phys. D 29, 939 (1996).

[12] D. Sander, S.O. Valenzuela, D. Makarov, C.H. Marrows, E.E. Fullerton, P. Fischer, J. McCord, P. Vavassori, S. Mangin, P. Pirro, B. Hillebrands, A.D. Kent, T. Jungwirth, O. Gutfleisch, C.G. Kim, A. Berger. J. Phys. D 50, 363001 (2017).

[13] P. Rinklin, H. Krause, B. Wolfrum. Lab. Chip. 16, 4749 (2016).

[14] M. Vázquez, M. Hernández-Vélez, A. Asenjo, D. Navas, K. Pirota, V. Prida, O. Sánchez, J.L. Baldonedo. Physica B 384, 36 (2006).

[15] A.S. Antonov, N.A. Buznikov, A.L. D’yachkov, A.A. Rakhmanov, V.V. Samsonova, T.A. Furmanova. J. Commun. Techn. Electron. 54, 1315 (2009).

[16] A. Zhukov, V. Zhukova, J.M. Blanco, A.F. Cobeño, M. Vazquez, J. Gonzalez. J. Magn. Magn. Mater. 258-259, 151 (2003).

[17] R.B. Morgunov, O.V. Koplak, V.P. Piskorskii, D.V. Korolev, R.A. Valeev, A.D. Talantsev. J. Magn. Magn. Mater. 497, 16604 (2019).

[18] О.В. Коплак, Е.В. Дворецкая, К.С. Кравчук, А.С. Усейнов, Д.В. Королев, Р.А. Валеев, В.П. Пискорский, О.С. Дмитриев, Р.Б. Моргунов. ФТТ 62, 2062 (2020).

[19] Yu. Kabanov, A. Zhukov, V. Zhukova, G. Gonzalez. Appl. Phys. Lett. 87, 142507 (2005).

[20] Y. Henry, K. Ounadjela, L. Piraux, S. Dubois, J.M. George, J.L. Duvail. Eur. Phys. J. B 20, 35 (2001).

[21] R. Varga, K.L. García, M. Vázquez, A. Zhukov, P. Vojtanik. Phys. Rev. B 70, 024402 (2004).

[22] J. Yamasaki, F.B. Humphrey, K. Mohri, H. Kawamura, H. Takamure, R. Mälmhäll. J. Appl. Phys. 63, 3949 (1988).

[23] D.J. Sellmyer, S. Nafis. J. Magn. Magn. Mater. 54-57, 1173 (1986).

[24] J. McCord. J. Phys. D 48, 333001 (2015).

[25] K. Richter, A. Thiaville, R. Varga. Phys. Rev. B 96, 064421 (2017).

[26] Y. Oshiai, S. Hashimoto, K. Aso. Jpn. J. Appl. Phys. 28, L1824 (1989).

[27] C. Mugonia, C. Gattob, A. Pla-Dalmauc, C. Siligardia. J. NonCryst. Solids 471, 295 (2017).

[28] X.M. Zang, D.S. Li, E.Y.B. Pun, H. Lin. Opt. Mater. Exp. 7, 2040 (2017).

[29] H. Takashima, K. Ueda, M. Itoh. Appl. Phys. Lett. 89, 261915 (2006).

[30] E.N. Kablov, O.G. Ospennikova, E.I. Kunitsyna, V.P. Piskorskii, D.V. Korolev, R.B. Morgunov. Arch. Met. Mater. 62, 1923 (2017).

Редактор К.В. Емцев 